University of Wollongong

Research Online

Partnerships, Proof and Practice - International

Nonprofit and Social Marketing Conference

Faculty of Arts, Social Sciences \& Humanities

2008 - Proceedings

7-2008

\title{
Communication About Organ Donation Intentions: Formative Research for a Social Marketing Program Targeting Families
}

Sandra C. Jones

University of Wollongong, sandraj@uow.edu.au

Samantha Reis

University of Wollongong, sreis@uow.edu.au

K. L. Andrews

University of Wollongong, kellym@uow.edu.au

Follow this and additional works at: https://ro.uow.edu.au/insm08

\section{Recommended Citation}

Jones, Sandra C.; Reis, Samantha; and Andrews, K. L., "Communication About Organ Donation Intentions: Formative Research for a Social Marketing Program Targeting Families" (2008). Partnerships, Proof and Practice - International Nonprofit and Social Marketing Conference 2008 - Proceedings. 5.

https://ro.uow.edu.au/insm08/5

Research Online is the open access institutional repository for the University of Wollongong. For further information contact the UOW Library: research-pubs@uow.edu.au 


\title{
Communication About Organ Donation Intentions: Formative Research for a Social Marketing Program Targeting Families
}

\author{
Abstract \\ With the introduction of the Australian Organ Donation Register (AODR), responsibility regarding organ \\ donation decisions primarily rests with the individual. However, family members can be instrumental in \\ facilitating or hindering the rate of organ donation by objecting to or confirming the individual's wishes. \\ Attitudes and beliefs of family members have been shown to be a strong influence on people's intentions \\ to donate. Numerous studies have also demonstrated that family communication about organ donation \\ can improve the rate of organ donation. We surveyed 23 matched pairs of undergraduate university \\ students and their parents and found that attitudes to organ donation were positive and that there was a \\ tendency for these dyads to give concordant responses regarding attitudes, level of family \\ communication and intent to donate. The implications of these findings are valuable to the development \\ of social marketing messages to improve Australia's organ donation rate.

\section{Publication Details} \\ This conference paper was originally published as Jones, S. C., Reis, S. and Andrews, K., Communication \\ About Organ Donation Intentions: Formative Research for a Social Marketing Program Targeting Families, \\ Partnerships, Proof and Practice - International Nonprofit and Social Marketing Conference 2008, \\ University of Wollongong, 15-16 July 2008.
}




\title{
Communication About Organ Donation Intentions: Formative Research for a Social Marketing Program Targeting Families
}

\author{
Sandra C. Jones, Samantha Reis, Kelly L. Andrews \\ Centre for Health Initiatives, University of Wollongong
}

\begin{abstract}
With the introduction of the Australian Organ Donation Register (AODR), responsibility regarding organ donation decisions primarily rests with the individual. However, family members can be instrumental in facilitating or hindering the rate of organ donation by objecting to or confirming the individual's wishes. Attitudes and beliefs of family members have been shown to be a strong influence on people's intentions to donate. Numerous studies have also demonstrated that family communication about organ donation can improve the rate of organ donation. We surveyed 23 matched pairs of undergraduate university students and their parents and found that attitudes to organ donation were positive and that there was a tendency for these dyads to give concordant responses regarding attitudes, level of family communication and intent to donate. The implications of these findings are valuable to the development of social marketing messages to improve Australia's organ donation rate.
\end{abstract}

\section{Introduction}

Organ transplantation saves many lives, and improves the quality of life of many more. While most countries have far more people on waiting lists for organ transplants than the number of organs actually donated, Australia currently has one of the lowest donation rates in the developed world (Australians Donate 2006). In 2004 there were 218 donors in Australia (10.8 donors per million population [dpmp]). In 2005, there were 1,800 individuals waiting for a transplant in Australia; and it was estimated that one in six died waiting for a transplant (David Hookes Foundation 2006).

\section{Family communication about organ donation}

Despite new legislation in Australia where families are now informed of their loved ones decision to donate, rather than asked to consent to follow through with the intention of their loved one, if families show strong resistance to this decision, donation will not proceed. As a result, efforts are being made to identify the best ways to stimulate individuals into a behavioural responsei.e. actually signing a donor card and communicating this act to family members.

While consent decisions tend to be heavily influenced by the family's own attitudes towards organ donation, a large proportion of families act in accordance with the wishes of the deceased when their preference is known in advance of their death (Radecki and Jaccard 1997; Martínez, López et al. 2001; Thompson, Robinson et al. 2003). Radecki and Jaccard (1997) report that if the next-of-kin are aware of the deceased's willingness to donate, there is a $93 \%$ compliance rate with this request. However, several studies have found that half of those who wish to donate have not made their wishes known to their family (Guadagnoli, Christiansen et al. 1999). 
Recent studies regarding communication about organ donation intentions have based their findings on asking people whether they would be willing to discuss organ donation with their families (Morgan, Miller et al. 2002; Morgan and Miller 2002) or asking individuals whether they have had such a discussion (Guadagnoli, Christiansen et al. 1999; Thompson, Robinson et al. 2003; Morgan 2004). A study with 149 university students in the US compared reported willingness to sign a letter of intention with the actual behaviour of signing and sending the letter. Over $50 \%$ of those who reported being quite, or extremely willing to sign did not when actually given the opportunity (Radecki and Jaccard 1999) suggesting that the intention to donate may not be a strong predictor of registering as a donor and that willingness alone is clearly not enough to stimulate action.

Other variables, allowing a more complete picture of organ donation warrant exploration, such as family communication. We identified only one study that investigated organ donation attitudes and decisions in family pair dyads (Morgan, Harrison et al. 2005); focusing on how the media influences opinions about organ donation. However, as data collection occurred within the dyads ( in videotaped discussions addressing a series of questions), it cannot be concluded whether attitudes were similar and/or communication had occurred prior to participation in the study.

\section{The Current Study}

The present study aims to add to previous research regarding organ donation by examining responses of student-parent dyads in terms of their attitudes about organ donation, their intentions to donate and, most importantly, their recollections of having discussed their decision (not) to be an organ donor with their family.

Most importantly, this research will extend previous findings by examining the concordance between responses of parents and their adult children, particularly in terms of their reported level of family communication. Communication is a two-way process, which can only be effectively achieved (and lead to desired behavioural outcomes) where both parties have the same, or at least similar, recollection of what was communicated. If one member of a dyad recalls circumstances differently, the behavioral outcome may not result. Thus examining the match between parents and their children is an integral part of this study.

In this way, the present research may hold the following implications:

i) If parents and students do show concordant responses to one another (in terms of attitudes, intentions and communication) this may provide some evidence for the intergenerational transmission of these attitudes; and,

ii) If parents and children do both recall having a discussion about organ donation, this discussion may have influenced their decision to donate/not to donate.

\section{Method}

Participants were recruited through undergraduate classes at a large regional university. One of the researchers attended lecture classes, provided an overview of the study, and distributed envelopes containing two identical surveys. One of the surveys had a reply paid envelope stapled to it - students were asked to take this home to a parent to complete and return. Students were 
requested to complete their copy of the survey 'on the spot' and these were personally collected by the researcher. The surveys had a handwritten numerical code to enable matching of returned pairs while maintaining the anonymity of respondents. The study was approved by the university's Human Research Ethics Committee, and all participants were assured of the confidentiality of their responses and the voluntary nature of their participation.

\section{Measures}

A single self-report measure was utilised for both parents and students. Questions varied in structure, but most were assessed on a 5-point likert scale (strongly agree-strongly disagree) or a binomial response (yes-no).

- Measure of attitudes to organ donation; Items 1-11 of the questionnaire aimed to address attitudes to organ donation on a 5-point likert scale. The attitudes total score was comprised of the sum of items referring to the moral justification of organ donation, support for organ donation, discussing organ donation, and attitudes to medical staff.

- Measure of intention to donate; Assessed by a single item: "I intend to donate my organs after death”. Agreement with this statement was indicated on a 5 point likert scale.

- Measure of decision to donate/ not donate; Assessed by the frequencies of responses to the items: "Why have you decided to be an organ donor?" and "Why have you decided NOT to be an organ donor". Non-reponse to this question was indicative of an "undecided" response.

- Informing the family of decision to donate; Assessed primarily using the question: "Have you informed your family of your decision (to donate/not donate)", to which binomial yes/ no responses were generated.

- Discussion of organ donation within the family; This was measured using a single item: "Has your family discussed the topic of organ donation?" (yes-no). As communication is conceptualised in this study as relying on the recollection of both parties - parents and students - additional statistics will examine the responses of dyads where both parent and child have reported the same response (i.e., yes and yes, or no and no).

\section{Results}

Completed responses were received from 23 dyads. The majority of respondents were female (83\% and $78 \%$ of the student and parent samples respectively); $96 \%$ of the students were aged 18 to 25 years and $61 \%$ of the parents aged 45 to 55 years; $86 \%$ of the students were single and $78 \%$ of the parents partnered/married.

\section{Attitudes towards organ donation and self reported 'intention to donate'}

Attitudes: Consistent with previous studies, both student and parent respondents expressed positive attitudes towards organ donation, with $78 \%$ of students and $83 \%$ of parents strongly supporting organ donation, [and 74\% and 57\% strongly agreeing that they intend to donate their organs after death]. When all 11 attitude items (on a 1-5 scale) were summed it was revealed that students had a slightly more positive attitude towards organ donation than parents, but this difference was minor ( 4.5 out of 5 compared to 4.4 out of 5 ). There was also a significant positive 
correlation between students' and their parents' responses to the attitude questions $(\mathrm{r}=.53, \mathrm{p}<$ .01 ), indicating that parents tended to have the same attitudes as their children.

Intentions: In terms of correspondence between dyads, there was a 65\% concordance rate within dyads for the question "I intend to donate my organs after my death"; that is, 15 out of the 23 dyads gave identical answers to this question. Out of those who gave concordant answers, most reflected a strong intention to be organ donors - 11/15 concordant dyads responded "strongly agree”, 3/15 dyads responded "agree” and only 1 dyad responded "not sure”. These results provide evidence that while students may hold slightly more positive attitudes to organ donation, parent and student attitudes were significantly correlated, and that there was some concordance between parents and their children in terms of their self reported intentions to donate.

\section{Family communication about organ donation and decisions about organ donation}

Deciding to be an organ donor and informing the family: All but one student $(\mathrm{n}=22)$ indicated that they had decided to become an organ donor. The remaining student reported being undecided. Overall, this indicates a strong tendency to make a decision to be an organ donor, regardless of whether one has discussed this with their family or not. In this case however, all 22 students reported having informed their family of their decision. Overall, 19 parents reported that they had decided to become an organ donor and four parents reported being undecided. No parents indicated that they had decided NOT to be an organ donor. Additionally, 16/19 parents (84\%) said that they had informed the family of their decision, and three that they had not.

In terms of dyadic concordance for decisions to be an organ donor, 20 out of the 23 pairs gave matched responses to the question. Of those 20 dyads who gave concordant responses, 19 responded that they had decided to be an organ donor and only one dyad reported being undecided.

Discussion of organ donation within family: Almost all of the students (91\%, $\mathrm{n}=20)$ reported they had discussed organ donation with their families, and those who had done so again appeared on average to have more positive attitudes (a score of 4.54 compared to 4.09 for those who said no). However, $\mathrm{t}$-tests revealed that this difference was not significant $(\mathrm{t}=2.19$, n.s.), as is due to the very small number who replied in the negative. Among the parent respondents, 17/23 (73\%) reported that they had discussed organ donation with their families, and again those who had done so displayed slightly more positive attitudes than those who said no (mean score of 4.59 compared to 3.90 for those who said no), but this difference was not significant $(t=5.02, n . s)$.

There was an 83\% concordance rate for dyads (19/23) in response to this question ("Has your family discussed organ donation”), and almost all responses (17/19) were in the affirmative, suggesting that the majority (17/23) of parents and students BOTH recalled having a discussion about organ donation.

Of the 17 dyads who both said they had engaged in a discussion about organ donation, all the students (17/17) said they had decided to become a donor, and almost all the parents had decided to become a donor (15/17), with the remainder undecided. Of the two dyads who both said they had not engaged in a conversation about organ donation with their family, both parents (2/2), and both children (2/2) had also made the decision to become a donor. 


\section{Discussion}

By and large, results indicate that parents and students share a generally positive attitude to organ donation, and most report an intention to donate their organs. As there was a high degree of concordance between responses of parents and children, there was some evidence for intergenerational transmission of attitudes towards organ donation. However, without controlling for other factors, such as shared exposure to organ donation information and promotion, or perhaps shared personal experiences with an organ receiver (for example), no exclusive or causal link between family discussions and decisions about organ donation can be established. This appears to be a valuable area for future research.

Family discussion about organ donation appeared to have a small, positive effect on attitudes to organ donation, but this result was not large enough to reach significance, possibly due to the small sample size, and the presence of a 'ceiling effect' in terms of both attitudes to organ donation and intentions/decisions to donate. That is, because such a high proportion of participants had decided to be an organ donor, the data has a restricted range and does not include enough variability to enable a meaningful comparison between participants.

However, many useful points have been gleaned from this research, including the idea that parental attitudes towards organ donation are likely to be passed on to, and shared with their children, influencing the consistency within families regarding intentions to donate. We also revealed that families who discussed organ donation tended to have slightly more positive attitudes towards organ donation, however it was interesting to note that families who had not discussed organ donation had still decided to become donors. It would be of interest to future research informing social marketing campaigns to examine any message variables in relation to the 'communicators' versus the 'non-communicators' - when both appear to have positive attitudes and intentions.

Radecki \& Jaccard (1999) suggest that key predictors of the breakdown between intention to communicate the decision to donate and actual communication are the perceived importance of the decision and the potential donor's confidence that they will be able to resist pressure from family members to change their minds; and that effective communication campaigns (in our context, social marketing campaigns) should focus on increasing knowledge of organ transplantation to assist intenders to counter misperceptions from family members, and on increasing both confidence and decision importance. Similarly, Morgan and Miller (2002) conclude that an effective campaign to increase organ donation will depend on potential donors' capacity to initiate and engage in effective family communication; and that the campaign should focus on promoting communication while simultaneously increasing knowledge, addressing misperceptions, and increasing positive attitudes.

Future research should examine the nature of family communication about organ donation (i.e., whether families discuss organ donation in a positive or negative light, and whether these conversations are in fact arguments involving different viewpoints), and the context in which it is discussed (i.e., spontaneously, or in response to a television show or public service announcement, or as a response of personal experience with organ donation). These topics would be very useful particularly in terms of social marketing. 


\section{References}

Australians Donate. (2006). "Be informed: Facts and figures." from http://www.australiansdonate.org.au/11655+0+facts-and-figures.htm

Australians Donate. (2006). "Website for Australian Donate." Retrieved June, 2007, from http://www.australiansdonate.org.au. .

David Hookes Foundation. (2006). "David Hookes Foundation Web Page." Retrieved 31/07/07, from

http://www.davidhookesfoundation.com/index.asp?d=5A4C5A715251477C70080608010904.

Guadagnoli, E., C. Christiansen, et al. (1999). "The public's willingness to discuss their

preference for organ donation with family members." Clinical Transplantation 13(4): 342-348.

Martínez, J. M., J. S. López, et al. (2001). "Organ donation and family decision-making within the Spanish donation system." Social Science \& Medicine 53(4): 405-421.

Morgan, S., J. Miller, et al. (2002). "Signing cards, saving lives: an evaluation of the worksite organ donation promotion project." Communication Monographs 69(3): 253 - 273.

Morgan, S. E. (2004). "The Power of Talk: African Americans' Communication with Family Members about Organ Donation and Its Impact on the Willingness to Donate Organs." Journal of Social and Personal Relationships 21(1): 112-124.

Morgan, S. E., T. R. Harrison, et al. (2005). "Family discussions about organ donation: how the media influences opinions about donation decisions." Clinical Transplantation 19(5): 674-682.

Morgan, S. E. and J. K. Miller (2002). "Beyond the Organ Donor Card: The Effect of Knowledge, Attitudes, and Values on Willingness to Communicate About Organ Donation to Family Members." Health Communication 14(1): 121 - 134.

Radecki, C. M. and J. Jaccard (1997). "Psychological Aspects of Organ Donation: A Critical Review and Synthesis of Individual and Next-of-Kin Donation Decisions." Health Psychology 16(2): 183-195.

Radecki, C. M. and J. Jaccard (1999). "Signing an Organ Donation Letter: The Prediction of Behavior From Behavioral Intentions1." Journal of Applied Social Psychology 29(9): 1833-1853.

Thompson, T. L., J. D. Robinson, III, et al. (2003). "Gender differences in family communication about organ donation (1)." Sex Roles: A Journal of Research 49(11-12): 587(10). 